\title{
Hemodynamic Instability
}

National Cancer Institute

\section{Source}

National Cancer Institute. Hemodynamic Instability. NCI Thesaurus. Code C99536.

A state of hypoperfusion that does not support normal organ perfusion or function. It can include periods of reduced, unstable, or abnormal blood pressure with near syncope, or episodes of syncope. 